\title{
Torque Ripple Reduction of a Direct-Drive Permanent-Magnet Synchronous Machine by Material-Efficient Axial Pole Pairing
}

\author{
W. Fei, P. C. K. Luk, Senior Member, IEEE
}

\begin{abstract}
This paper investigates a material-efficient axial pole pairing method for torque ripple reduction in a direct-drive outer-rotor surface-mounted permanent-magnet synchronous machine. The effects of the magnet pole arc width on the torque ripple characteristics of the machine are first established by both analytical and two-dimensional finite element approaches. Furthermore the effectiveness of the axial pole pairing technique in mitigating the machine cogging torque, back electromotive force harmonics and overall torque quality is comprehensively examined. Finally three-dimensional finite element analysis and experiments are carried out to validate the proposed approach, and the results show that axial pole pairing can be cost-efficiently implemented in terms of magnet material usage and assembly.
\end{abstract}

Index Terms-Axial pole pairing, back electromotive force, cogging torque, direct drive, finite element analysis, fractional slot, magnet pole arc width, permanent magnet synchronous machine, torque ripple reduction.

\section{NOMENCLATURE}

$A_{n N}$

$\alpha_{p}$

$\alpha_{p j}$

$B_{a g}$

$B_{\text {mag }}$

$B_{n}$

$B_{n N}$

$e$

$e_{a}, e_{b}, e_{c}$

$E_{1}$

$E_{6 n \pm 1}$

$i$

$i_{a}, i_{b}, i_{c}$

$I_{1}$

$\varphi$

$k_{w n}$
Phase angle of the $n N^{\text {th }}$ harmonic of $B_{\text {mag }}$.

Magnet pole arc width ratio.

Magnet pole arc width ratio of the $j^{\text {th }}$ magnet set. Open-circuit air gap radial magnetic flux density. Open-circuit air gap radial magnetic flux density without slot effect consideration

Peak value of the $n^{\text {th }}$ harmonic of $B_{\text {mag }}$.

Peak value of the $n N^{\text {th }}$ harmonic of $B_{\text {mag }}$.

Phase back electromotive force (EMF).

Back EMFs of phase $a, b, c$.

Peak value of the fundamental component of phase back EMF.

Peak value of the $(6 n \pm 1)^{\text {th }}$ harmonic of phase back EMF.

Magnet set number.

Currents of phase $a, b, c$.

Peak value of the fundamental component of phase current.

Electrical angle by which current leads the back EMF.

Winding factor of the $n^{\text {th }}$ harmonic.

Manuscript received December 29, 2010. Accepted for publication May 19 2011.

Copyright $(2009$ IEEE. Personal use of this material is permitted. However, permission to use this material for any other purpose must be obtained from the IEEE by sending a request to pubs-permissions@ieee.org.

W. Fei and P. C. K. Luk are with Department of Engineering and Applied Science, Cranfield Defence and Security, Cranfield University, Shrivenham, SN6 8LA, U. K. (e-mail: achimao@hotmail.com; p.c.k.luk@cranfield.ac.uk ). $l_{e}$

$l_{e j}$

$\lambda_{a g}$

$\lambda_{m}$

$\lambda_{n N}$

$\mu_{0}$

$N$

$N_{s}$

$p$

$p_{s}$

$\theta_{r}$

$\theta_{s}$

$r_{g}$

$r_{m}$

$r_{s}$

$T_{c}$

$T_{e}$

$T_{m}$

$\omega_{r}$

$\mathrm{D}$ IRECT-DRIVE systems that involve no mechanical transmission trains and gearboxes have been attracting considerable interests in electric propulsion applications in recent years [1-5]. A key reason for the popularity is the general perception that they enjoy higher efficiency and higher reliability due to the absence of the mechanical gears used in conventional drive systems. Since high performance direct-drives require motors with high torque density to develop tractive force directly at the shaft, high strength rare earth permanent magnet synchronous machines (PMSMs) with an outer rotor configuration are considered an ideal candidate. This is because the outer-rotor PMSM has highest torque density among other permanent magnet (PM) machine configurations with similar ratings. However, in a direct-drive, the absence of mechanical gears means that the adverse effects of torque ripple generated at the shaft of a PMSM is unabated. In addition, the use of high strength rare earth magnets not only results in high average torque, but also generates high cogging torque. Furthermore, it is becoming strategically more important to embrace machine designs that minimize the wastage rate in the usage and assembly of rare-earth magnets, due to growing demand and uncertain supply dynamics in the future. 
For surface mounted PMSMs (SM-PMSMs), the torque ripple comprises of two main components:

1) Load-independent cogging torque arising from the permanent magnets' tendency to align themselves with the minimum reluctance paths formed by varying relative positions between the rotor and the stator;

2) Load-dependent torque pulsation due to the interactions between the harmonics of armature currents driven into the machine and the harmonics of the distorted sinusoidal back electromotive forces (EMFs).

In addition, magnetic saturations in the stator and rotor cores will further exasperate the output torque of the machine [6]. Accordingly, torque ripple minimization techniques can be categorized into machine design based and machine control based [7]. The former concerns the optimization of cogging torque and back EMF during electromagnetic design stage of the machine, whilst the latter mainly concerns the optimal control of armature current during operation of the machine. Control methods with varying degrees of sophistication have been developed to mitigate the torque ripple while driving the PMSMs on line [8-14]. On the other hand, a host of machine design techniques have been proposed to reduce cogging torque and harmonic contents of the back EMF, and hence torque pulsation, of the PMSMs, including magnet shaping [15-18], magnet pole arc width (MPAW) and skewing [19-22], combinations of the stator slot and rotor pole number [23,24], magnet segmentation [25-27], magnet pole pairing [28-30] and other more sophisticated optimizations [31-33]. It is noteworthy, from the techniques surveyed, that there are invariably performance tradeoffs in the implementation of these optimization schemes. In addition, there appears no apparent interest on the efficient usage of magnet materials in the existing studies.

This paper concerns a machine design based torque ripple reduction scheme for a high performance direct-drive system used in an electric propulsion application. In [30], a novel axial pole pairing method is first proposed, solely as an alternative cogging torque suppression technique to other conventional cogging torque reduction methods, for an outer-rotor SM-PMSM. As such, its utility as a new method in improving the machine's overall torque performance in a wider context, such as under loaded conditions, has not been established. Moreover, its potential in optimizing the usage of magnet material has not been discussed. This paper further investigates into the viability and limitations of the axial pole pairing method in torque ripple minimization, which considers the combined effects of cogging torque, back EMF harmonics, and loading conditions. Significantly, the study will reveal that the magnet pole pairs for minimum torque ripple, unlike the ones solely for minimum cogging torque, are dependent on the loading conditions of the machine. In Section II, an approximate analytical model is developed to estimate the cogging torque, back EMF, and torque ripple of the SM-PMSM In Section III, the outer rotor SM-PMSM is introduced and analyzed by the analytical and 2-D FEA approaches. In Section $\mathrm{IV}$, the impacts of MPAW on the cogging torque, back EMF harmonics, and overall torque pulsation of the proposed machine are studied using analytical and two-dimensional (2-D) finite element analysis (FEA) models. Section V is devoted to detailed analysis and implementation of the axial pole pairing method in the minimization of cogging torque and torque ripples of the machine, with highlights on its assembly- and material-efficient aspects. Furthermore, in Section VI, both three-dimensional (3-D) FEA and experimental results are presented to validate the analytical and synthesized 2-D FEA models, followed by conclusions in Section VII.

\section{Analytical Modeling OF TORQUe RiPPle}

Recently, computationally efficient FEA methods have been developed to investigate the torque ripple characteristics in interior PM machines [34,35], for which closed-form analytical models are practically infeasible. However, they generally give no hints as to how the machine parameters are related to the torque features. A simplified closed-form analytical model, which can be easily derived in a SM-PMSM, can however provide useful insight into the ways in which the machine's performance can be optimized with reasonable accuracy. Generally, the reluctance torque in SM-PMSM can be ignored as a result of negligible rotor saliency. Thus the instantaneous torque output of a three phase SM-PMSM can be easily derived by omitting the leakage inductance and saturation of the magnetic circuit as

$T_{m}=\frac{e_{a} i_{a}+e_{b} i_{b}+e_{c} i_{c}}{\omega_{r}}+T_{c}$

In order to decouple the controller-induced nonlinearities, the current in the winding is assumed to be balanced and sinusoidal. Thus, the first term in the right side of equation (1), the electromagnetic torque $T_{e}$, can be rewritten as

$T_{e}=\frac{3 I_{1}}{2 \omega_{r}} E_{1} \cos (\varphi)+\frac{3 I_{1}}{2 \omega_{r}} \sum_{n=1}^{\infty} E_{6 n \pm 1} \cos \left(6 n p \omega_{r} t \mp \varphi\right)$

To estimate the cogging torque and back EMF, hence instantaneous torque of the proposed machine, the open-circuit radial magnetic flux density in the air gap should be found, and the analytical expression of which in an SM-PMSM with unequal tooth widths can be presented as

$$
\begin{aligned}
B_{a g}\left(\theta, r_{g}\right)=\lambda_{a g} B_{\text {mag }}= & \sum_{m=0}^{\infty} \lambda_{m}\left(r_{g}\right) \cos \left(m p_{s} \theta_{s}\right) \\
& \times \sum_{n=1,3,5 \ldots}^{\infty} B_{n}\left(\alpha_{p}, r_{g}\right) \cos \left(n p\left(\theta_{s}-\theta_{r}\right)\right)
\end{aligned}
$$

where detailed derivations of $\lambda_{\mathrm{ag}}$ and $B_{\text {mag }}$ can be found in [36] and [37] respectively. The cogging torque of the machine can be calculated by virtual work method as

$$
\begin{aligned}
T_{c}\left(\theta_{r}\right)= & \frac{N}{4 \mu_{0}} l_{e}\left(r_{m}^{2}-r_{s}^{2}\right) \\
& \times \sum_{n=1}^{\infty} n B_{n N}^{2}\left(\alpha_{p}\right) \lambda_{n N}^{2} \sin \left(A_{n N}^{2}\left(\alpha_{p}\right)\right) \sin \left(n N \theta_{r}\right)
\end{aligned}
$$




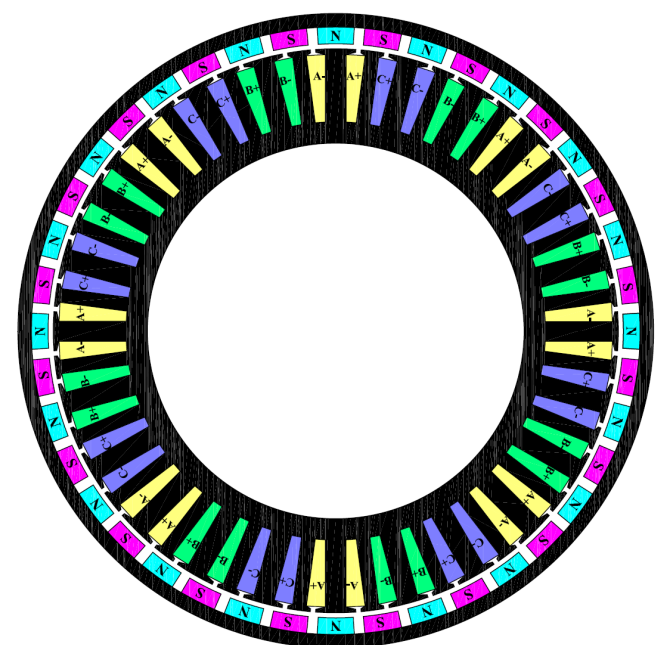

Fig. 1. Schematic of the proposed permanent magnet synchronous machine.

TABLE I

KEY DESIGN PARAMETERS OF THE MACHINE

\begin{tabular}{lc}
\hline \hline \multicolumn{1}{c}{ Parameters } & Values \\
\hline Number of phases & 3 \\
DC power supply & $180 \mathrm{~V}$ \\
Rated power output & $6000 \mathrm{~W}$ \\
Rated rotational speed & $2000 \mathrm{rpm}$ \\
Number of magnet poles & 40 \\
Number of stator slots & 48 \\
Rotor outer diameter & $189 \mathrm{~mm}$ \\
Rotor inner diameter & $181 \mathrm{~mm}$ \\
Magnet thickness & $5 \mathrm{~mm}$ \\
Magnet pole arc width & $8.0 \mathrm{degree}$ \\
Air gap length & $1.5 \mathrm{~mm}$ \\
Slot opening width & $2 \mathrm{~mm}$ \\
Stator tooth width & $6.18 \mathrm{~mm}$ and $4.1 \mathrm{~mm}$ (uneven) \\
Stator tooth shoe span & 7.89degree and 4.39degree (uneven) \\
Slot depth & $20 \mathrm{~mm}$ \\
Axial length & $30 \mathrm{~mm}$ \\
Number of turns per coil & 94 \\
Magnet material & NdFe35SH \\
Stator core material & $20 \mathrm{THT} 1500$ \\
\hline \hline
\end{tabular}

The back EMF can be evaluated from the air gap radial flux density near the stator poles. Here, the back EMF of individual phase is computed by the time derivative of the phase flux linkage as

$$
\begin{aligned}
e= & 2 r_{s} l_{e} \omega_{r} N_{s} \\
& \times \sum_{n=1,3,5 \ldots}^{\infty} B_{n}\left(\alpha_{p}, r_{s}\right)\left(\sum_{m=0}^{\infty} \frac{k_{w n} n^{2} p^{2} \lambda_{m}\left(r_{s}\right)}{(n p)^{2}-\left(m p_{s}\right)^{2}}\right) \sin \left(n p \theta_{r}\right)
\end{aligned}
$$

Equations (4) and (5) provide the closed-form solutions for the torque ripple and back EMF characteristics of the SM-PMSM. Although simplified assumptions have been made, this approach allows a rapid determination of the feasible design range, within which the optimal design resides.

\section{Outer-Rotor Direct-Drive SM-PMSM}

The outer-rotor topology lends itself to a direct-drive motor since it provides the maximum torque density for a given power output among other stator-rotor topologies. Moreover, fractional-slot configurations with similar stator slot and rotor

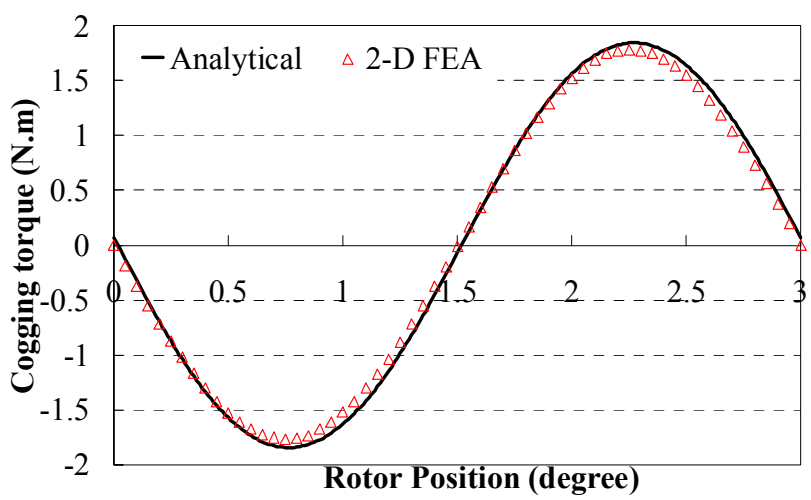

Fig. 2. Comparison of cogging torque between analytical and 2-D FEA models.

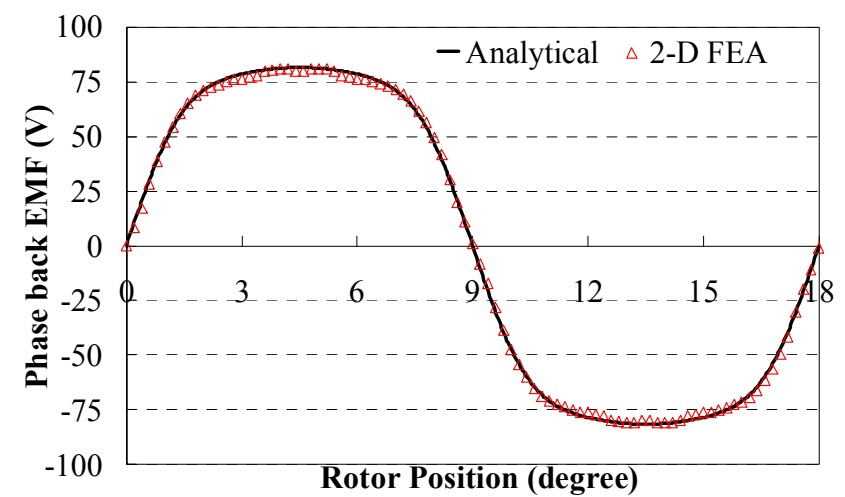

Fig. 3. Comparison of phase back EMF at 2000rpm between analytical and 2-D FEA models.

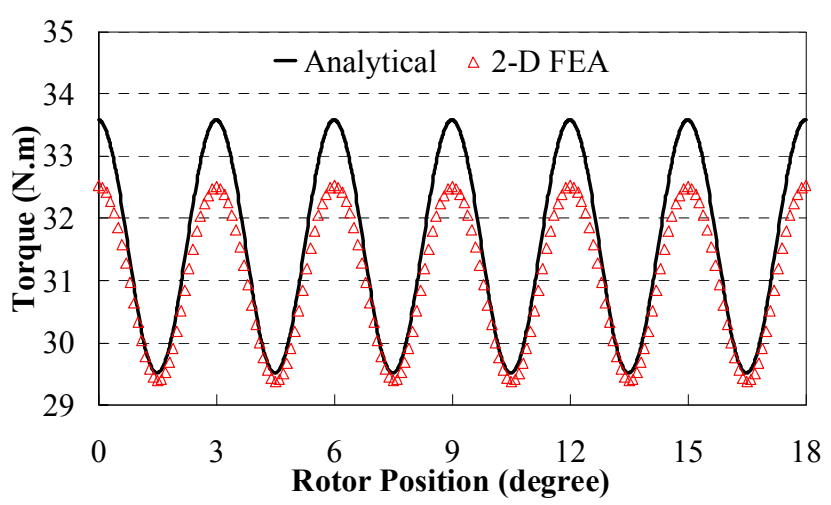

Fig. 4. Comparison of output torque at rated current 34A (rms) between analytical and 2-D FEA models.

numbers, furnished by concentrated coils with shortened end windings, offer distinct advantages of high efficiency, compactness and good fault tolerance [38-40]. Thus, as shown in Fig.1, the proposed machine is an outer-rotor direct-drive PMSM with 40 magnet poles and 48 stator poles, and employs unequal stator tooth widths together with single-layer concentrated windings to achieve near-unity winding factor [41-43]. High strength parallel magnetized rare earth PMs $(\mathrm{NdFe} 35 \mathrm{SH})$ are mounted on the inner surface of the back iron ring, while single-layer concentrated coils are wound around the wider stator poles to achieve high fill factor and flux linkage. Each phase winding has eight identical stator coils connected in parallel. As such the coils are physically isolated from one another by the narrower stator poles. This results in negligible 


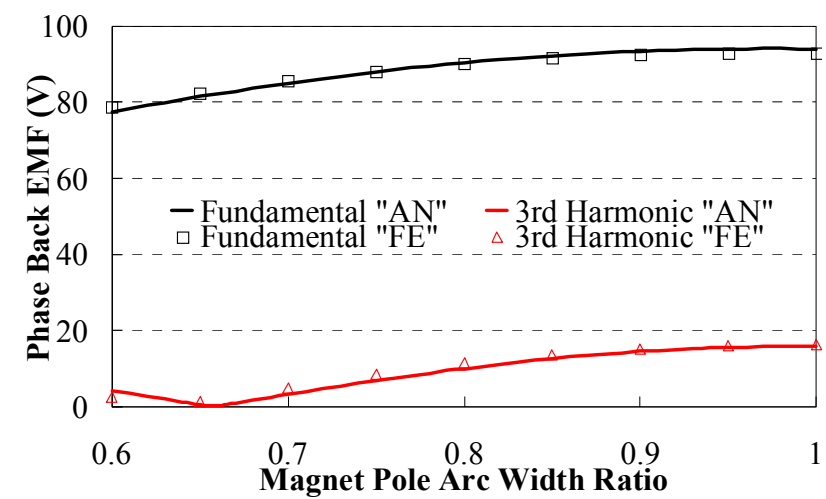

(a) Fundamental and third harmonics

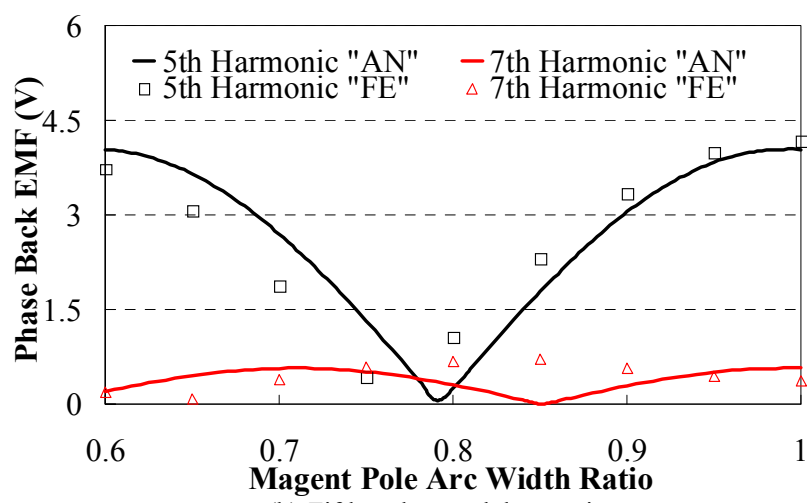

(b) Fifth and seventh harmonics

Fig. 5. Phase back EMF characteristics for different MPAW from analytical (“AN") and 2-D FEA ("FE") models.

mutual inductance and good fault tolerance. Moreover, $0.2 \mathrm{~mm}$ Nippon Steel 20HTH1500 laminated sheets are used to minimize stator core losses at high electrical frequency. The key design parameters of the machine are given in Table I.

The original machine based on Table I is modeled in 2-D FEA in order to validate the analytical model presented in Section II. Fig.2 compares the machine's cogging torque profiles by the analytical and 2-D FEA models, whilst Fig.3 compares that of the phase back EMF at the rated speed of 2000rpm. Both show excellent agreements between the outputs of the models. Fig.4 further compares the overall torque output waveforms at the rated phase current of $34 \mathrm{~A}(\mathrm{rms})$ from the two models. Since the analytical model assumes no magnetic saturation at the stator core, it tends to give higher outputs than the 2-D FEA model, where magnetic saturations are accounted for. Thus, the peak-to-peak (P-P) torque ripples are found to be $4.07 \mathrm{~N} \cdot \mathrm{m}$ and $3.14 \mathrm{~N} \cdot \mathrm{m}$ respectively from the analytical and $2-\mathrm{D}$ FEA models. And for the average torque, they are $31.6 \mathrm{~N} \cdot \mathrm{m}$ and $31.0 \mathrm{~N} \cdot \mathrm{m}$ respectively. Fig. 4 also shows that the torque ripples have a predominant $6^{\text {th }}$ harmonic, contributed mainly by the considerable cogging torque. Overall, the results from Fig.2 to Fig.4 show that analytical model provides useful estimations of the performance of the machine at the initial stage of design.

\section{Magnet Pole ArC Width}

In SM-PMSMs, it is known that the rotor MPAW has a direct effect on the harmonic content of back EMF and the magnitude of cogging torque [15]. There exists an optimum MPAW value

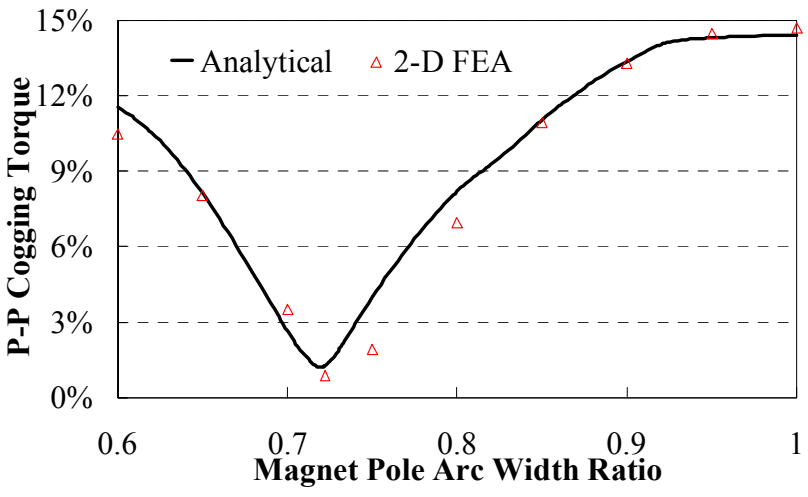

Fig. 6. Variation of cogging torque with MPAW.

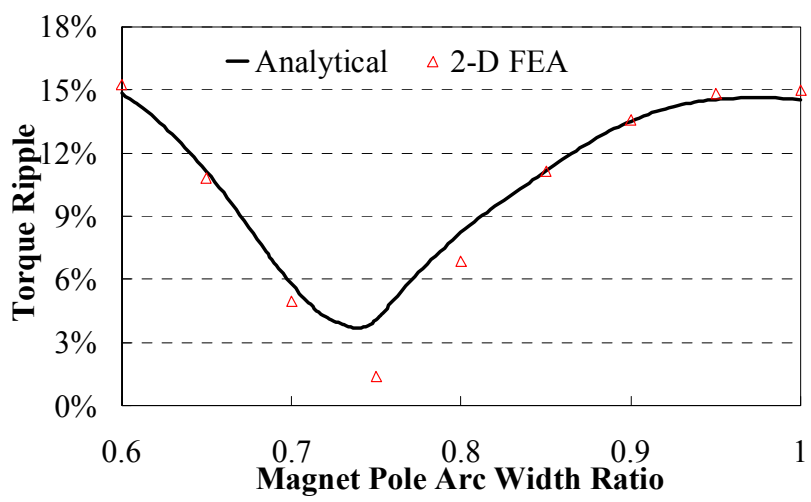

Fig. 7. Variation of torque ripple with MPAW at rated output torque.

for minimum flux harmonics, and another one for minimum cogging torque, respectively. Since cogging torque and flux harmonics represent the two key sources of torque ripple in the machine, the impacts of the MPAW on them are examined by analytical and 2-D FEA models respectively. Finally, the effect of the MPAW on the overall torque quality has been revealed.

\section{A. Flux Harmonics}

Air-gap flux harmonic contents, which would give rise to back EMF harmonics, are greatly influenced by the MPAW [15]. Fig.5 shows the fundamental, $3^{\text {rd }}, 5^{\text {th }}$ and $7^{\text {th }}$ harmonic contents of the phase back EMF as a function of the MPAW, by the analytical and 2-D FEA models. Whilst the fundamental and $3^{\text {rd }}$ harmonics from the analytical model agree well with the ones from 2-D FEA in Fig.5 (a), there are apparent deviations in Fig.5 (b) for the $5^{\text {th }}$ and $7^{\text {th }}$ harmonics as a result of local saturation effects in the stator pole shoe areas. Though the $3^{\text {rd }}$ harmonic components, which can be virtually eliminated when the MPAW ratio reaches about 0.66 , are quite significant, it will be eradicated internally in a three phase machine. The $5^{\text {th }}$ and $7^{\text {th }}$ harmonics, inspected from equation (5) as the most significant ones, achieve their minimum when MPAW ratios are about 0.79 and 0.85 respectively from the analytical model, and 0.75 and 0.65 respectively from the FEA model. Furthermore, the agreements between the analytical and 2-D FEA results for the $5^{\text {th }}$ harmonic is closer than the ones for $7^{\text {th }}$, and the $5^{\text {th }}$ harmonic is considerably larger than the $7^{\text {th }}$. On the whole, the fundamental component of the phase back EMF, in common with the machine output torque, increases gradually with MPAW. 

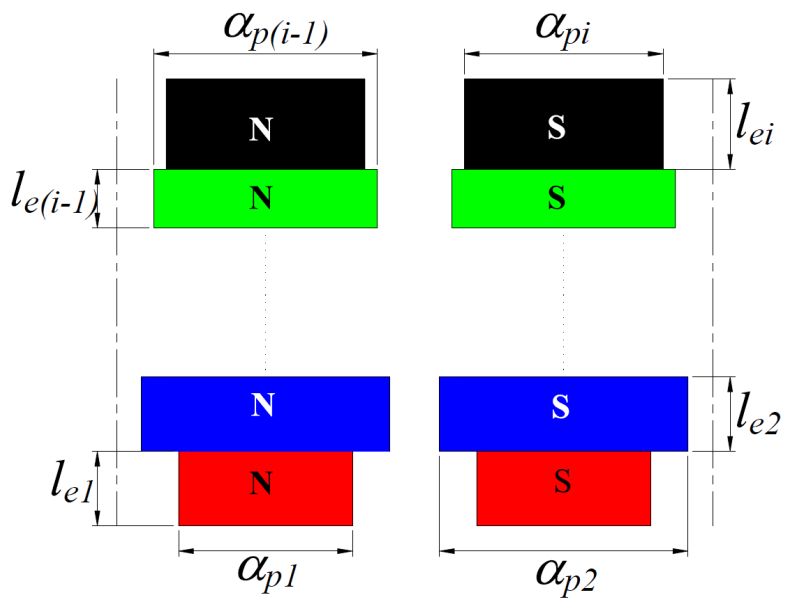

Fig. 8. Schematic of the axial pole pairing method.

\section{B. Cogging Torque}

The P-P cogging torque values, normalized to the rated output torque of the machine, are computed over a viable range of MPAW by analytical and 2-D FEA approaches as shown in Fig.6. The variations follow a ' $V$ ' shape with a minimum at the optimal MPAW. It is important to note that this optimal value, which separates the two regions with opposite polarities of cogging torque, is load independent [30]. It can clearly be seen that the analytical and 2-D FEA results are in close agreements, and the optimal MPAW ratio is found to be about 0.72 .

\section{Overall Torque Quality}

In order to investigate the effects of the MPAW on the overall torque quality of the machine during loaded conditions, the torque quality evaluations of the machine are carried out by analytical and 2-D FEA models with different current excitations such that the machine delivers the same rated torque with different MPAW ratios. Fig.7 shows the torque ripple for the machine with different MPAW. It follows a similar ' $V$ ' shape variation as in Fig.6, such that the optimal MPAW at the trough of the curve also splits the two regions with opposing torque polarities. Unlike for cogging torque, the optimal MPAW for minimum torque ripple is load-dependent. Again, good agreements between the analytical and FEA results are achieved. It shows the optimal MPAW ratio for minimum torque ripple for the rated torque is about 0.75 , which is slightly larger than the optimal ratio of 0.72 for minimum cogging torque, due to the loading effects.

\section{AXIAl Pole PAIRING}

As an alternative to the conventional circumferential pole pairing technique, a novel axial pole pairing technique, depicted in Fig. 8, has been proposed to reduce the cogging torque in permanent magnet machines [30]. As illustrated, the magnet pairs can consist of a variety of different axial lengths as well as different pole arc width. It can be seen that the new technique can offer distinct advantages in terms of efficient use of magnet material and ease of assembly over other cogging torque reduction methods. Analytically, the axial pole pairing

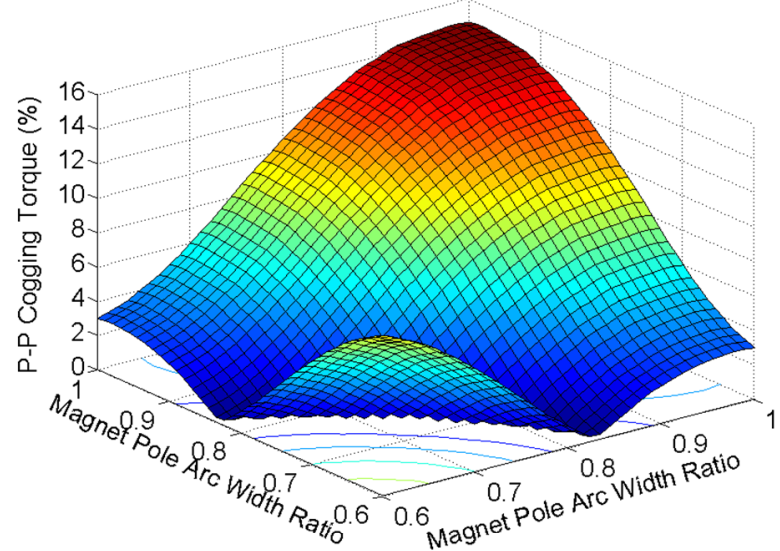

Fig. 9. P-P cogging torque for magnet pairs with varying MPAW.

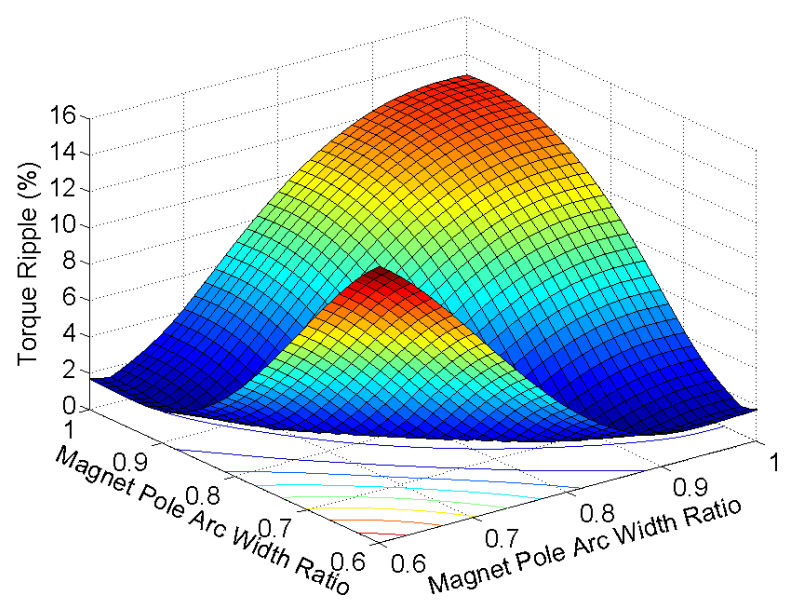

Fig. 10. Torque ripple for magnet pairs with varying MPAW.

technique can be treated as several machines with different axial-lengths but the same stator configuration axially conjoined together. Thus, by assuming that the axial interactions between the magnets are negligible, the cogging torque and phase back EMF can be derived respectively in the following as

$$
\begin{aligned}
T_{c}\left(\theta_{r}\right) & \simeq \frac{N}{4 \mu_{0}}\left(r_{m}^{2}-r_{s}^{2}\right) \\
\times & \sum_{j=1}^{i} \sum_{n=1}^{\infty} n l_{e j} B_{n N}^{2}\left(\alpha_{p j}\right) \lambda_{n N}^{2} \sin \left(A_{n N}^{2}\left(\alpha_{p j}\right)\right) \sin \left(n N \theta_{r}\right)
\end{aligned}
$$

$e=2 r_{s} \omega_{r} p^{2}$

$\times \sum_{j}^{i} \sum_{n=1,3,5 \ldots}^{\infty} l_{e j} B_{n}\left(\alpha_{p j}, r_{s}\right)\left(\sum_{m=0}^{\infty} \frac{k_{w n} n^{2} \lambda_{m}\left(r_{s}\right)}{(n p)^{2}-\left(m p_{s}\right)^{2}}\right) \sin \left(n p \theta_{r}\right)$

In a similar manner, the 2-D FEA results for each machine section with their corresponding axial length can be used to synthesize the resultant effect for the entire machine. The analytical equations, together with the synthesized 2-D FEA models aforementioned, thus allow the optimal magnet pair to be tactfully selected for the machine's best torque performance. Without loss of generality, this paper investigates only two sets 


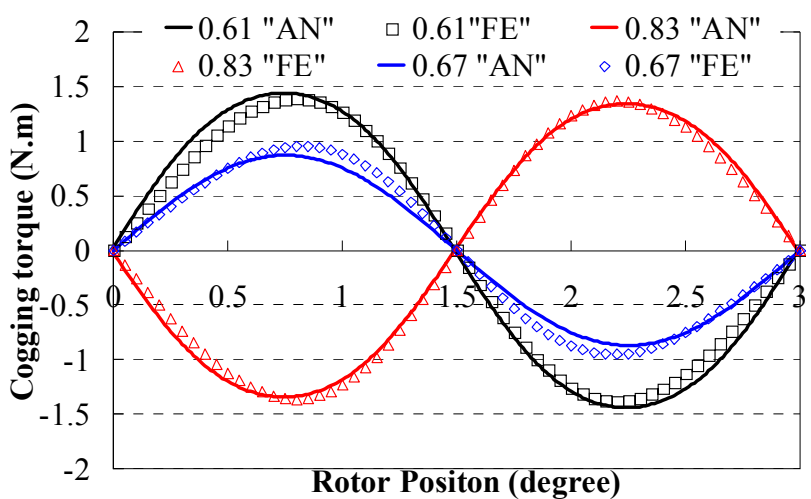

Fig. 11. Cogging torque waveforms for the machines with $0.61,0.67,0.83$ MPAW predicted by analytical ("AN") and 2-D FEA ("FE") models.

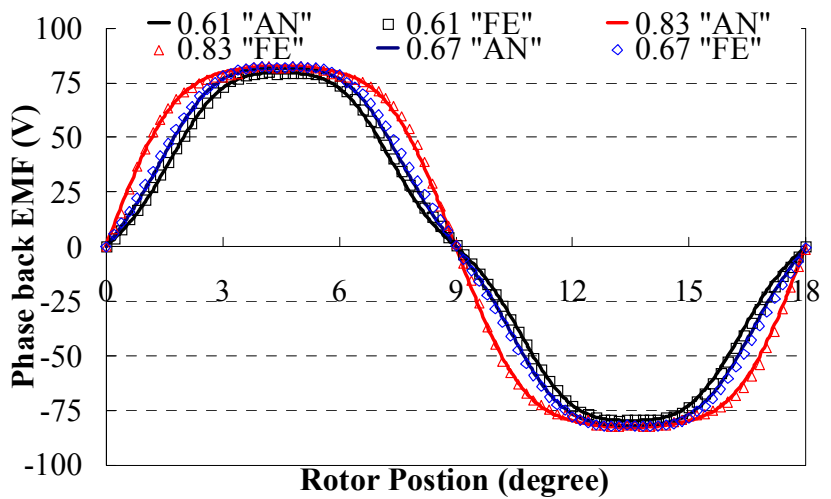

Fig. 12. Phase back EMF waveforms for the machines with $0.61,0.67,0.83$ MPAW predicted by analytical ("AN") and 2-D FEA ("FE") models.

TABLE II

HARMONIC ANALYSIS OF PHASE BACK EMF FOR FIG.12

\begin{tabular}{c|ccc}
\hline \hline & \multicolumn{4}{|c}{ Amplitude (V)/Phase Angle(Degree) } \\
\cline { 2 - 4 } & 0.61 "AN"("FE”) & 0.67 "AN"("FE") & 0.83 “AN"("FE") \\
\hline $1^{\text {st }}$ & $79.3(79.5) /-90(-90)$ & $85.7(85.6) /-90(-90)$ & $91.5(91.2) /-90(-90)$ \\
$3^{\text {rd }}$ & $3.41(1.96) / 90(90)$ & $0.79(2.61) /-90(-90)$ & $11.8(12.8) /-90(-90)$ \\
$5^{\text {th }}$ & $4.00(3.52) / 90(90)$ & $3.48(2.82) / 90(90)$ & $1.30(2.22) /-90(-90)$ \\
$7^{\text {th }}$ & $0.27(0.15) / 90(-90)$ & $0.53(0.21) / 90(90)$ & $0.11(0.58) / 90(90)$ \\
\hline \hline
\end{tabular}

of magnet pole pairs with same axial lengths. From Fig.5 and Fig.7, there are potentially infinite possible magnet pole pairs that can effectively suppress the cogging torque and the torque ripple, the rule of thumb being that the pair should generate equal and opposing torque ripples. This is further illustrated in Fig.9 and Fig.10, which show the normalized P-P cogging torque and torque ripple for different magnet pairs evaluated from the synthesized 2-D FEA models, respectively. It follows that the average MPAW ratios of the magnet pairs for minimum cogging torque and torque ripple are 0.72 and 0.75 , respectively. The final selection of the optimal magnet pair for overall torque ripple reduction should take loading conditions into consideration.

\section{A. Case Study of Selected Optimal Magnet Pairs}

For further investigation, the magnet pair of $5.5^{\circ}(0.61)$ and $7.5^{\circ}(0.83) \mathrm{MPAW}$, which have an average of $0.72 \mathrm{MPAW}$, is selected for minimum cogging torque. And the magnet pair of $6.0^{\circ}(0.67)$ and $7.5^{\circ}(0.83) \mathrm{MPAW}$, which has an average of $0.75 \mathrm{MPAW}$, is selected for minimum torque ripple at rated phase current 34A (rms). Fig. 11 compares the cogging torques

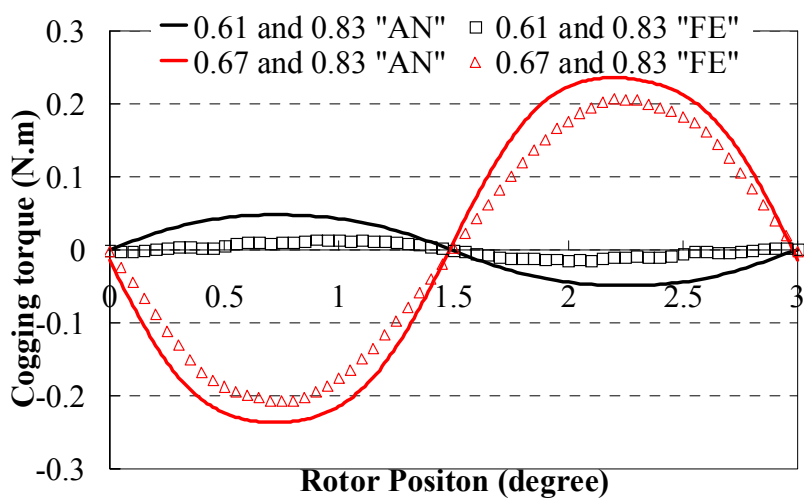

Fig. 13. Cogging torque waveforms with the proposed axial pole pairs from analytical ("AN") and synthesized 2-D FEA ("FE") models.

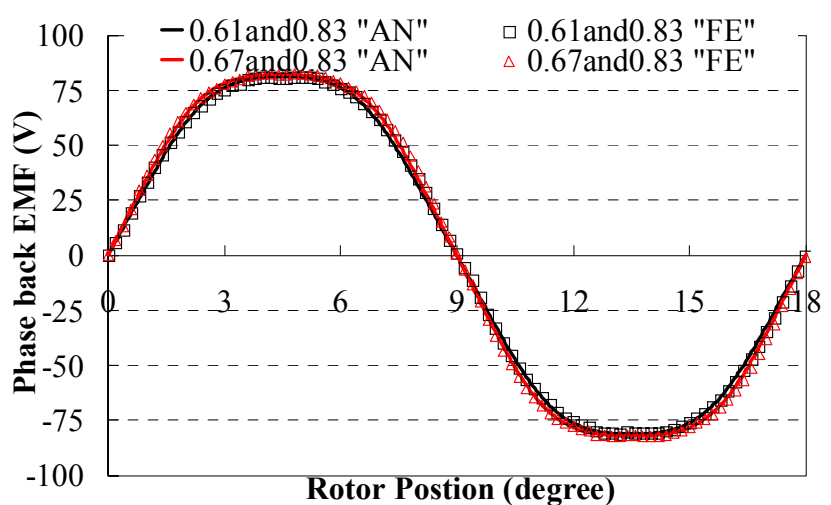

Fig. 14. Phase back EMF waveforms with the proposed axial pole pairs from analytical ("AN") and synthesized 2-D FEA ("FE") models.

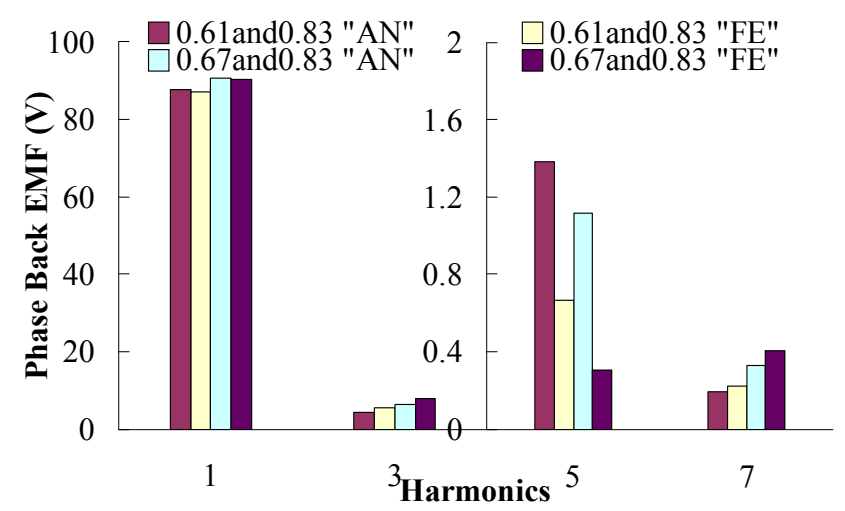

Fig. 15. Harmonic spectrum of the phase back EMF with the proposed axial pole pairs from analytical ("AN") and synthesized 2-D FEA ("FE") models.

for the machines with $0.61,0.67$, and 0.83 MPAW ratios as predicted by the analytical and 2-D FEA models, and confirms that the cogging torque waveforms of the machines with 0.61 and 0.83 MPAW have similar but opposite peak values, resulting in nearly full cancellation of cogging torque. Pairing with 0.67 MPAW, however, will only result in partial cancellation due to the smaller peak values. Fig. 12 compares the corresponding phase back EMF waveforms at rate speed by the two models, which show overall excellent agreements. To probe further into the harmonic contents, Table II presents the values of the main harmonics of the phase back EMF shown in Fig. 12. There are notable deviations between the analytical and 2-D FEA results of $5^{\text {th }}$ and $7^{\text {th }}$ harmonics of the phase back 


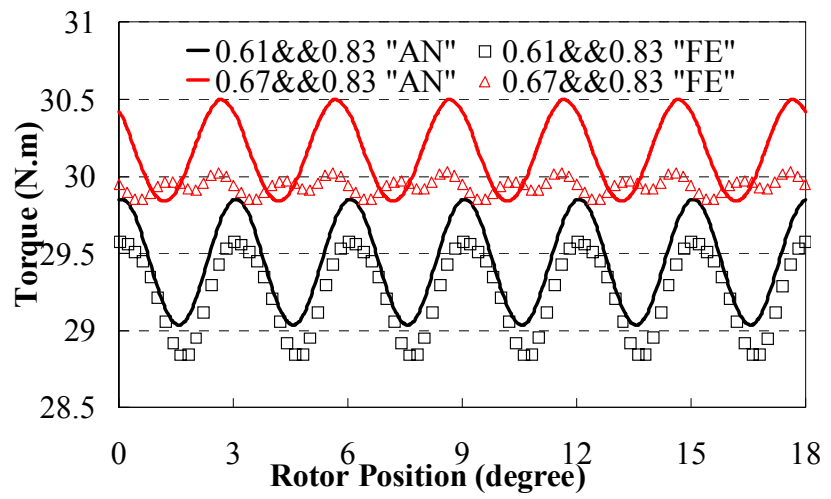

Fig. 16. Torque waveforms for the machine with the proposed axial pole pairs at rated phase current 34A (rms) from analytical ("AN") and synthesized 2-D FEA ("FE") models.

EMF, and the polarities of $7^{\text {th }}$ harmonics from 2-D FEA results are reversed. These discrepancies suggest that the analytical models become more inaccurate for the higher back EMF harmonics prediction due to higher levels of saturation and flux leakage.

\section{B. Cogging Torque and Phase Back EMF Predictions}

The cogging torque and phase EMF performance of the machine with the proposed axial pole-pairs of $0.61 / 0.83$ MPAW and $0.67 / 0.83$ MPAW are predicted by the analytical and synthesized 2-D FEA models. Fig.13 shows that the cogging torque can be effectively reduced to very low levels with the pole-pair of $0.61 / 0.83 \mathrm{MPAW}$, but to still considerable levels for the $0.67 / 0.83 \mathrm{MPAW}$ pair. Also, there are noticeable discrepancies between the analytical and synthesized 2-D FEA results, which confirm the assumption made does not account for material nonlinearity in the analytical model. Fig. 14 compares the phase back EMF profiles at rated speed by the two models, and Fig. 15 shows the corresponding harmonic spectra. Better agreements between the models, however, are shown in these cases. Having taken account for the nonlinearity of the lamination material, the synthesized 2-D FEA model yields a slightly smaller fundamental component of the phase back EMF than that of the analytical model. However, the reverse is true for the $3^{\text {rd }}$ harmonics, which would nonetheless be eradicated in a 3-phase system. As expected, relatively large discrepancies between the analytical and synthesized 2-D FEA for higher harmonics $\left(5^{\text {th }}\right.$ and $\left.7^{\text {th }}\right)$ have been revealed. However, all models show relatively small $5^{\text {th }}$ and $7^{\text {th }}$ harmonics, which underline the effectiveness of the selected pole-pairs in generating good quality sinusoidal line back EMF.

\section{Overall Torque Quality Prediction}

The overall torque quality of the machine under load conditions is studied by exciting the machine windings with the rated current $34 \mathrm{~A}(\mathrm{rms})$. Fig. 16 shows the complete torque profiles predicted by the two models for each of the selected axial pole-pairs respectively. For the $0.61 / 0.83$ MPAW pair, the estimated average torque is $29.45 \mathrm{~N} \cdot \mathrm{m}$ and $29.25 \mathrm{~N} \cdot \mathrm{m}$ respectively by the analytical and synthesized 2-D FEA models For the $0.67 / 0.83 \mathrm{MPAW}$ pair, it is $30.16 \mathrm{~N} \cdot \mathrm{m}$ and $29.94 \mathrm{~N} \cdot \mathrm{m}$ respectively. These follow the same pattern as the fundamental

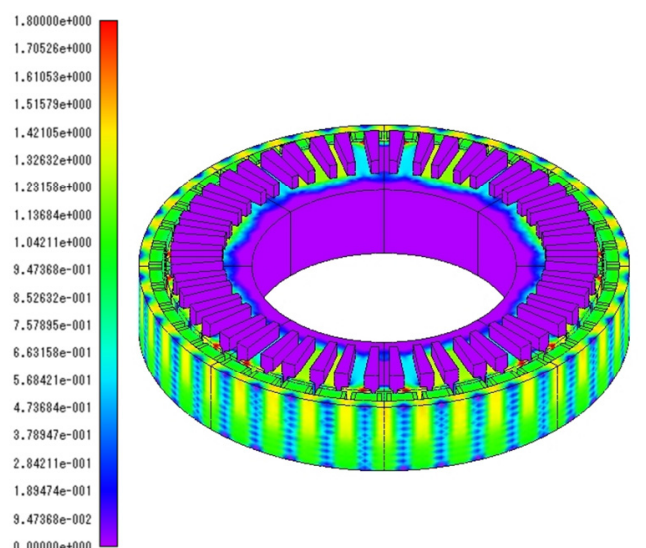

(a) No load condition

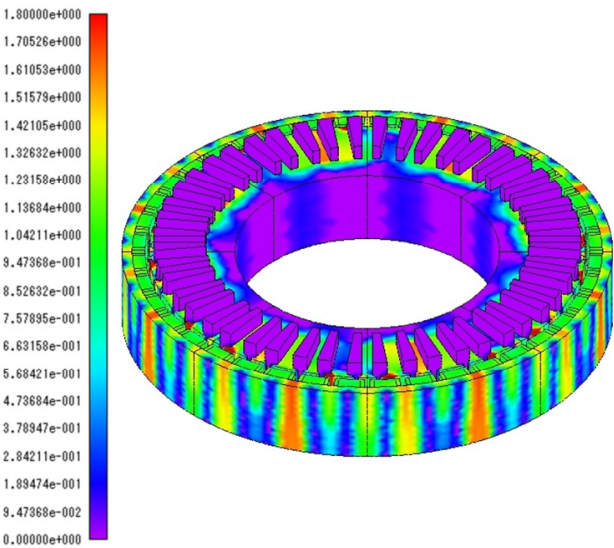

(b) Full load condition

Fig. 17. Flux density distributions of the machine with the proposed axial pole

component of phase back EMF for the similar reasons. The corresponding P-P torque ripples for the machine with the $0.61 / 0.83 \mathrm{MPAW}$ pole-pair are $0.82 \mathrm{~N} \cdot \mathrm{m}(2.7 \%)$ and $0.75 \mathrm{~N} \cdot \mathrm{m}$ $(2.5 \%)$, whilst the ones for the $0.67 / 0.83$ MPAW pole-pair are $0.66 \mathrm{~N} \cdot \mathrm{m} \quad(2.1 \%)$ and $0.18 \mathrm{~N} \cdot \mathrm{m} \quad(0.6 \%)$ respectively. By comparing with the results in Fig. 4, it is found that the P-P torque ripple of the original prototype can be drastically reduced by implementing axial pole pairing with the two proposed magnet pairs, at the expense of a small drop in the average torque output.

From the above comprehensive study, the magnet pole-pair which delivers minimum cogging torque would still produce quite noticeable torque ripples under load conditions due to the flux harmonics. On the other hand, the prominent $6^{\text {th }}$ harmonic cogging torque in the machine with the pole-pair which gives minimum torque ripples under rated load condition can be effectively counteracted by the torque pulsations generated by the $5^{\text {th }}$ and $7^{\text {th }}$ flux harmonics. However, the pole-pair could produce a relatively high level of torque pulsations under low or no load condition due to the load-independent cogging torque. Thus, the choice of the optimal pole-pair is very much dependent of the loading conditions and the operational envelope of the application. In general, the pole-pair for minimum cogging toque may be chosen as the optimal over a wide operational range especially at no load and light load conditions. 


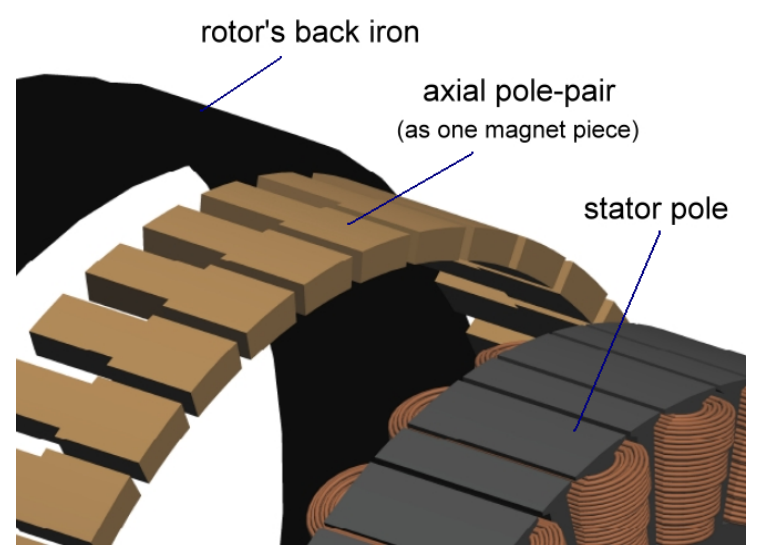

(a) Material-efficient axial pole pairing

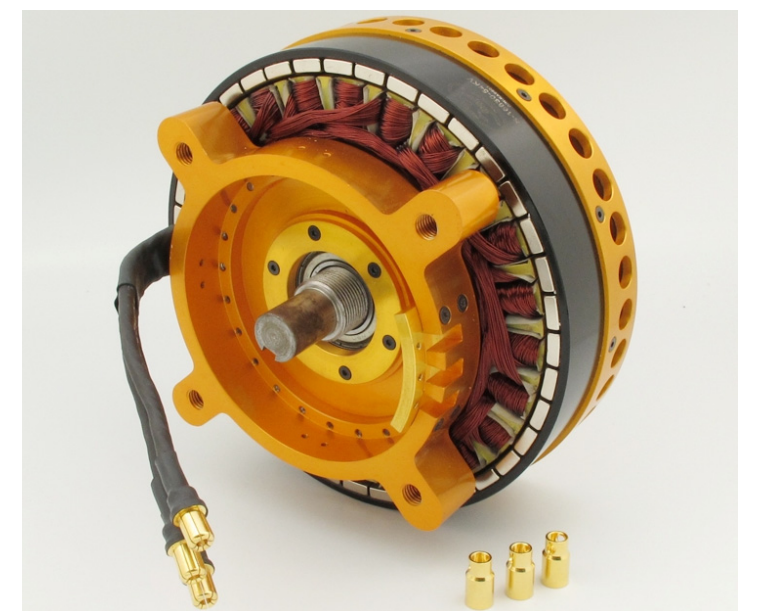

(b) Assembled prototype machine showing design for manufacturability

Fig. 18. Prototype machine implemented and built with the $0.61 / 0.83$ MPAW pole-pair for experimental validation

\section{3-D FEA AND EXPERIMENTAL VALIDATIONS}

This section describes the final phase of validations by $3-D$ FEA models and experimentation. The 3-D FEA model takes into account any further geometrical effects otherwise omitted in the 2-D FEA models, whilst experimental results provide the final validations of all the models developed, and as the acid test of the viability and practicality of the proposed method.

\section{A. 3-D FEA Model}

The 3-D FEA model accounts for the end effects and the axial magnetic interactions of the magnet pair so that the cogging torque, phase back EMF and torque ripple can be more accurately evaluated. Only one eighth of the proposed machine is modeled by periodic boundary conditions. Fig. 17 shows the flux density distributions of the machine with the pole-pair of 6.1/8.3 MPAW by the 3-D FEA model. In Fig.17(a), since there is no armature reaction under no load condition, there is hardly magnetic saturation. In Fig.17(b), there are obvious saturations in both the stator and rotor due to the significant armature excitation under full load condition, which would bring about additional torque pulsations. The 3-D model will take into full consideration these armature reactions to achieve more accurate torque ripple estimations. The results from the

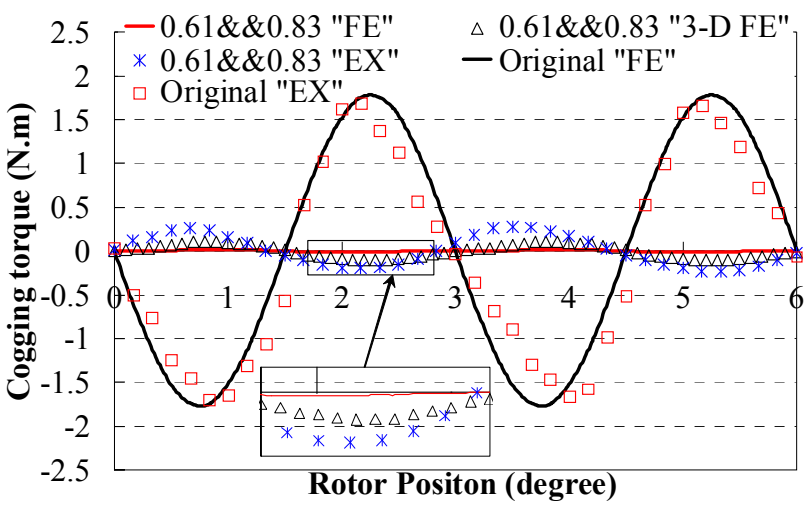

Fig. 19. Cogging torque waveforms for the two prototypes from 2-D FEA ("FE"), 3-D FEA ('3-D FE"), and experiments ("EX").

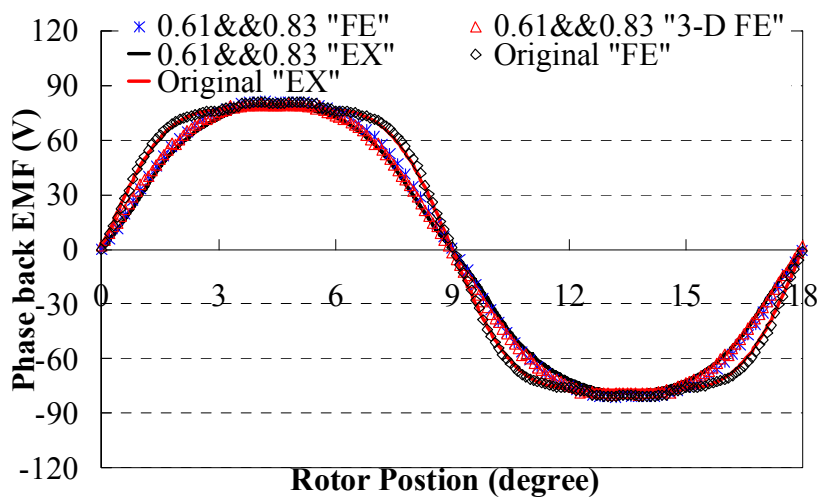

Fig. 20. Phase back EMF waveforms for the two prototypes from 2-D FEA ("FE"), 3-D FEA ("3-D FE"), and experiments ("EX").

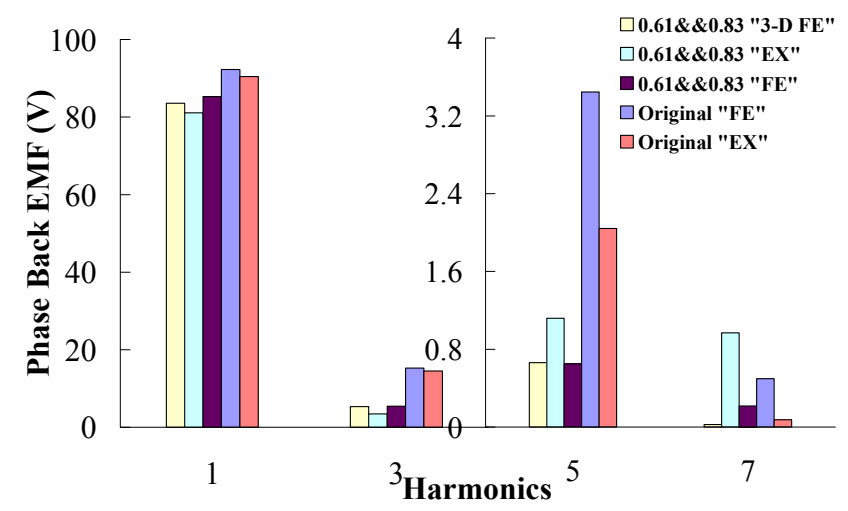

Fig. 21. Harmonic spectrum of the phase back EMF of the two prototypes from 2-D FEA ("FE"), 3-D FEA ("3-D FE"), and experiments ("EX").

3-D FEA model have revealed that the axial thrust forces caused by the proposed axial pole pairing are negligible.

\section{B. Prototyping Axial Pole Pairing}

In addition to the prototype machine with the original $8.0^{\circ}$ MPAW, a new prototype incorporating the axial pole pairing technique with the magnet pair of $5.5^{\circ}$ and $7.5^{\circ} \mathrm{MPAW}$ has been developed and built for experimental validations (i.e. only the $0.61 / 0.83$ pole-pair was selected for final tests), which is shown in Fig.18. To highlight the material-efficient and ease of assembly aspects of the axial pole pairing technique, Fig.18(a) illustrates how pole-pairing can be easily implemented with one piece of magnet to minimize material wastage rate. The 


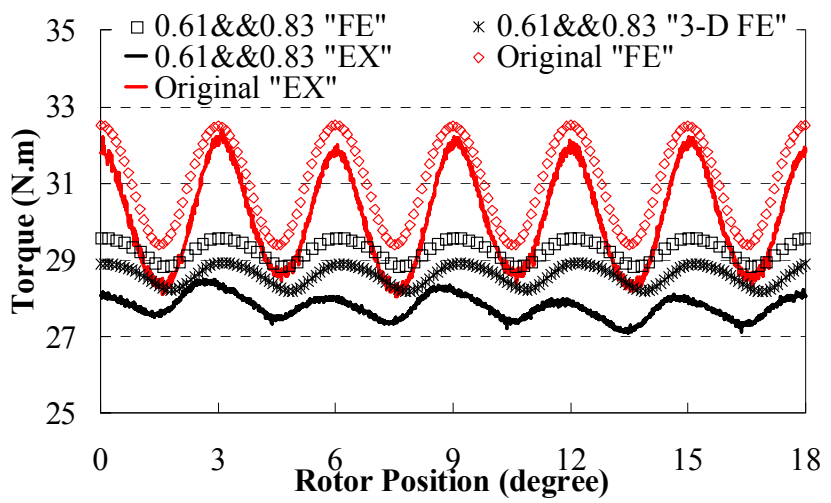

Fig. 22. Torque waveforms for the two prototypes at rated phase current $34 \mathrm{~A}$ (rms) from 2-D FEA ("FE"), 3-D FEA ("3-D FE"), and experiments ("EX")

regularly shaped pole-pair magnets are generally well suited to cost-efficient fabrication processes. Moreover, as illustrated in the fully assembled prototype in Fig.18(b), the magnets are all uniformly positioned and glued onto the back iron. Thus, assembly and the detection of misalignment of magnets can also be very cost-effectively achieved. On the contrary, circumferential pole-paring and other methods may involve fixation of non-uniformly shaped magnets [18], and on irregular patterns [28], resulting in heightened hazards and elevated costs in both assembly and detection of misalignment, which are important factors for design for manufacturability. Furthermore, since axial pole pairing preserves machine symmetry, it allows parallel connections of the coil in each phase and results in no unbalanced radial magnetic force that causes de-centering vibrations and wear of bearings.

\section{Experimental Validations}

This section involves the validation of the FEA models and the viability of the proposed axial pole pairing method by experimental tests. In Fig.19, the predicted cogging torque profiles of the prototype implemented with the $0.61 / 0.83$ MPAW pole-pair from the FEA models and experiments are compared against those of the prototype with the original $8.0^{\circ}$ MPAW. Significantly, the experimental results confirm that the cogging torque is drastically reduced by the axial pole pairing technique, from $3.39 \mathrm{~N} \cdot \mathrm{m}$ to $0.51 \mathrm{~N} \cdot \mathrm{m}$, or a nearly $85.0 \%$ reduction. They also show that the 3 -D FEA results for the prototype with $0.61 / 0.83 \mathrm{MPAW}$ pole-pair are closer to the experimental, and hence more accurate, than that of the 2-D model due to the consideration of axial interactions and end effects in the 3-D FEA model. Also, it is observed that generally there are relatively large discrepancies between the FEA and experimental results. Whilst the proposed FEA models assume perfect manufacture and assembly of the prototype machine, there are inevitably mechanical tolerances in manufacture and assembly deficiencies in practice. In particular, the machine has relatively large rotor dimensions (outer rotor configuration) and a high number of magnet poles, making it all the more difficult and costly for magnets to be cut and assembled to the designed tolerances. There are also errors due to lamination stacks assembly and stator-rotor eccentricity. In general, cogging torque is very sensitive to these machine parameters. Thus, taking these factors in consideration and allowing for errors due to measurement and instrumentation, the cogging torque results are considered satisfactory.

The phase back EMF waveforms of the two prototypes measured at rated speed, are compared with the corresponding 2-D and 3-D FEA ones in Fig. 20. Since measurement of voltage is normally less sensitive to mechanical deficiency of the machine and experimental errors than that of cogging torque, there are very close agreements between the predicted and measured results. To further investigate the phase back EMF, harmonic analysis has been undertaken as shown in Fig. 21 , which shows that the $5^{\text {th }}$ and $7^{\text {th }}$ harmonics are small but not negligible in practice, in particular the $5^{\text {th }}$ harmonic in the prototype with original $8.0^{\circ} \mathrm{MPAW}$ is quite noticeable. The fundamental component of the phase back EMF in the prototype with pole-pairing by the 3-D FEA is slightly smaller than the 2-D FEA one as a result of taking into account both the axial interactions and end effects. The ones from experimental measurement are about 3\% lower than the estimated ones. One main reason for this discrepancy is that the lamination stacking effects are not factored in the FEA models. Furthermore, it can be found that the fundamental component of the back EMF in the prototype with the original $8.0^{\circ} \mathrm{MPAW}$ is nearly $6 \%$ higher than the one in the prototype with axial pole-pairing.

Finally, loaded tests were performed on the two prototypes by feeding them with sinusoidally modulated current at a de-rated speed of 20rpm loaded with a dynamometer, to simulate a direct-drive application. The developed torques at rated current of 34A (rms) are shown in Fig.22, in which the 2-D and 3-D FE simulation results are also included for comparison. It is noted that the experimental torque waveforms have similar predominant $6^{\text {th }}$ harmonics as in the simulated results. For the prototype with original $8.0^{\circ} \mathrm{MPAW}$, the torque ripple is mainly due to its outstanding cogging torque, whilst for the one in the prototype with pole pairing, it is mainly formed by interactions between the fundamental current component with the $5^{\text {th }}$ as well as the $7^{\text {th }}$ harmonic in the back EMF as shown in Fig. 21. Besides, there are inevitable controller-induced torque ripples in practice. These explain the appearance of other harmonics in the measured torque ripples. Furthermore, due to the friction and lamination stacking factor effects, the average torque is reduced further in the experimental measurements. The average torque outputs of the prototype with original $8.0^{\circ} \mathrm{MPAW}$ from the 2-D FEA and experimental results are $31.02 \mathrm{~N} \cdot \mathrm{m}$ and $30.10 \mathrm{~N} \cdot \mathrm{m}$ respectively, while the corresponding P-P torque ripples are $3.14 \mathrm{~N} \cdot \mathrm{m}$ and $4.33 \mathrm{~N} \cdot \mathrm{m}$. The average torque outputs of the prototype with the 6.1/8.3 MPAW pole-pair from the 2-D, 3 -D FEA and experimental results are $29.25 \mathrm{~N} \cdot \mathrm{m}, 28.59 \mathrm{~N} \cdot \mathrm{m}$ and $27.78 \mathrm{~N} \cdot \mathrm{m}$ respectively, while the corresponding P-P torque ripples are $0.75 \mathrm{~N} \cdot \mathrm{m}, 0.70 \mathrm{~N} \cdot \mathrm{m}$ and $1.40 \mathrm{~N} \cdot \mathrm{m}$. Thus, the overall torque ripple of the machine is effectively reduced by $66.7 \%$ by axial pole pairing, but at the expense of a reduction of $7.7 \%$ of the overall average torque output of the machine.

\section{Selection of Optimal Pole Pairs}

Whereas the above experimental results for loaded conditions 
demonstrate the utility of axial pole pairing, they also further underline the load-dependence of selecting the optimal pole pairs. For a direct-drive application, where high torque at low speed can manifest prominently the most undesirable side effects caused by torque ripples, the choice of the optimal pair should be based on minimizing these effects at the given speed range. With the validated FEA models, many potential optimal solutions by specific magnet pole pairs can be readily generated. Nonetheless, the final selection of the optimal pole pair depends critically on the tactful considerations of the prospective load conditions of the application.

\section{CONCLUSION}

The new axial pole pairing technique for cogging torque and torque ripple reductions is investigated, and its utility in a special outer rotor three-phase PMSM with an uneven 48-slot 40-pole fractional slot configuration is comprehensively demonstrated by means of optimizations involving cogging torque, flux harmonic, and overall torque quality evaluations. Analytical and synthesized 2-D FEA models have been used in the optimization and performance predictions. Furthermore, 3-D FEA and experimental tests have been undertaken to validate the analytical and 2-D FEA results, as well as the proposed axial pole pairing technique itself.

In addition, it is shown that the proposed pole pairing is a material-efficient technique that can be implemented with minimum material wastage rate on rare earth magnets, and can benefit from ease of assembly and detection of magnet misalignment. Furthermore, although it is not implemented in the study, the technique also lends itself to axial magnet segmentation schemes for reduction of eddy current losses in the rotor. It is envisaged that the proposed axial pole pairing method can also be applied to other PM machines with different configurations such as the permanent magnet flux switching machine.

\section{ACKNOWLEDGMENT}

The authors gratefully acknowledge the motor manufacture expertise offered by Georges van Gansen of Scorpion Power System (H.K.), and the software support for the JMAG-Studio by Powersys.

\section{REFERENCES}

[1] K. M. Rahman, N. R. Patel, T. G. Ward, J. M. Nagashima, F. Caricchi, and F. Crescimbini, "Application of direct-drive wheel motor for fuel cell electric and hybrid electric vehicle propulsion system," IEEE Trans. Ind. Appl., vol. 42, no. 5, pp. 1185-1192, Sept./Oct. 2006.

[2] R. Wrobel, and P. H. Mellor, "Design considerations of a direct drive brushless machine with concentrated windings," IEEE Trans. Energy Convers., vol. 23, no. 1, pp. 1-8, March 2008.

[3] F. Chai, J. Xia, B. Guo, S. Cheng, and J. Zhang, "Double-stator permanen magnet synchronous in-wheel motor for hybrid electric drive system" IEEE Trans. Magn., vol. 45, no. 1, pp. 278-281, Jan. 2009.

[4] A. M. EL-Refaie, "Fractional-slot concentrated-windings synchronous permanent magnet machines: opportunities and challenges," IEEE Trans. Ind. Electron., vol. 57, no. 1, pp. 107-121, Jan. 2010.

[5] B. C. Mecrow, J. W. Bennett, A. G. Jack, D. J. Atkinson, and A. J. Freeman, "Drive topologies for solar-powered aircraft," IEEE Trans. Ind. Electron., vol. 57, no. 1, pp. 457-464, Jan. 2010.
[6] M. S. Islam, R. Islam, and T. Sebastian, "Experimental verification of design techniques of permanent-magnet synchronous motors for low-torque-ripple applications," IEEE Trans. Ind. Appl., vol. 47, no. 1, pp. 88-95, Jan./Feb. 2011.

[7] T. M. Jahns, and W. L. Soong, "Pulsating torque minimization techniques for permanent magnet AC motor drives-A review," IEEE Trans. Ind. Electron., vol. 43, no. 2, pp. 321-330, Apr. 1996.

[8] S. Chen, C. Namuduri, and S. Mir, "Controller-induced parasitic torque ripples in a PM synchronous motor" IEEE Trans. Ind. Appl., vol. 38, no. 5, pp. 1273-1281, Sept./Oct. 2002.

[9] P. Mattavelli, L. Tubiana, and M. Zigliotto, "Torque-ripple reduction in PM synchronous motor drives using repetitive current control," IEEE Trans. Power Electron., vol. 20, no. 6, pp. 1423-1431, Nov. 2005.

[10] G. H. Lee, S. I. Kim, J. P. Hong, and J. H. Bahn, “Torque ripple reduction of interior permanent magnet synchronous motor using harmonic injected current," IEEE Trans. Magn., vol. 44, no. 6, pp. 1582-1585, June 2008.

[11] K. Gulez, A. A. Adam, and H. Pastaci, "Torque ripple and EMI noise minimization in PMSM using active filter topology and field-oriented control," IEEE Trans. Ind. Electron., vol. 55, no. 1, pp. 251-257, Jan. 2008.

[12] C. Ortega, A. Arias, C. Caruana, J. Balcells, and G. M. Asher, "Improved waveform quality in the direct torque control of matrix-converter-fed PMSM drives," IEEE Trans. Ind. Electron., vol. 57, no. 6, pp. 2101-2110, June 2010.

[13] T. Shi, Y. Guo, P. Song, and C. Xia, "A new approach of minimizing commutation torque ripple for brushless DC motor based on DC-DC converter," IEEE Trans. Ind. Electron., vol. 57, no. 10, pp. 3483-3490, Oct. 2010 .

[14] Y. C. Zhang, J. G. Zhu, "Direct torque control of permanent magnet synchronous motor with reduced torque ripple and commutation frequency," IEEE Trans. Power Electron., vol. 26, no. 1, pp. 235-248, Jan. 2011.

[15] M. S. Islam, S. Mir, T. Sebastian, and S. Underwood, "Design considerations of sinusoidally excited permanent-magnet machines for low-torque-ripple applications," IEEE Trans. Ind. Appl., vol. 41, no. 4, pp. 955-962, July/Aug. 2005

[16] W. Fei, and P. C. K. Luk, "An improved model for the back EMF and cogging torque characteristics of a novel axial flux permanent magnet synchronous machine with a segmental laminated stator," IEEE Trans. Magn., vol. 45, no. 10, pp. 4609-4612, Oct. 2009 ..

[17] W. Fei, and P. C. K. Luk, "Torque ripple reduction of axial flux permanent magnet synchronous machine with segmented and laminated stator," in Proc. IEEE Energy Conversion Congress and Exposition, 2009, pp. 132-138.

[18] N. N. Chen, S. L. Ho, and W. N. Fu, "Optimization of permanent magnet surface shapes of electric motors for minimization of cogging torque using FEM," IEEE Trans. Magn., vol. 46, no. 6, pp. 2478-2481, June 2010 .

[19] M. Dai, A. Keyhani, and T. Sebastian, "Torque ripple analysis of a PM brushless DC motor using finite element method," IEEE Trans. Energy Convers., vol. 19, no. 1, pp. 40-45, March 2004.

[20] R. Islam, I. Husain, A. Fardoun, and K. McLaughlin, "Permanent-magnet synchronous motor magnet designs with skewing for torque ripple and cogging torque reduction," IEEE Trans. Ind. Appl., vol. 45, no. 1, pp. 152-160, Jan./Feb. 2009.

[21] L. Zhu, S. Z. Jiang, Z. Q. Zhu, C. C. Chan, "Analytical methods for minimizing cogging torque in permanent-magnet machines," IEEE Trans. Magn., vol. 45, no. 4, pp. 2023-2031, April 2009.

[22] L. Parsa, and L. Hao, "Interior permanent magnet motors with reduced torque pulsation," IEEE Trans. Ind. Electron., vol. 55, no. 2, pp. 602-609, Feb. 2008.

[23] K. Atallah, J. Wang, and D. Howe, "Torque-ripple minimization in modular permanent-magnet brushless machines," IEEE Trans. Ind. Appl., vol. 39, no. 6, pp. 1689-1695, Nov./Dec. 2003.

[24] S. H. Han, T. M. Jahns, W. L. Soong, M. K. Guven, and M. S. Illindala, "Torque ripple reduction in interior permanent magnet synchronous machines using stators with odd number of slots per pole pair," IEEE Trans. Energy Convers., vol. 25, no. 1, pp. 118-127, March 2010.

[25] R. Lateb, N. Takorabet, and F. Meibody-Tabar, "Effect of magnet segmentation on the cogging torque in surface-mounted permanent magnet motors," IEEE Trans. Magn., vol. 42, no. 3, pp. 442-445, March 2006. 
[26] B. Boukais, and H. Zeroug, "Magnet segmentation for commutation torque ripple reduction in a brushless DC motor drive," IEEE Trans. Magn., vol. 46, no. 11, pp. 3909-3919, Nov. 2010.

[27] M. Ashabani, and Y. A. -R. I. Mohamed, "Multiobjective shape optimization of segmented pole permanent-magnet synchronous machines with improved torque characteristics," IEEE Trans. Magn., vol. 47, no. 4, pp. 795-804, April 2011.

[28] N. Bianchi, and S. Bolognani, "Design techniques for reducing the cogging torque in surface-mounted PM motors," IEEE Trans. Ind. Appl., vol. 38, no. 5, pp. 1259-1265, Sep./Oct. 2002

[29] Y. Wang, M. J. Jin, W. Fei, and J. X. Shen, "Cogging torque reduction in permanent-magnet flux-switching machines by rotor teeth axial pairing," IET Electr. Power Appl., vol. 4, no. 7, pp. 500-506, Aug. 2010.

[30] W. Fei, and P. C. K. Luk, "A new technique of cogging torque suppression in direct-drive permanent magnet brushless machines," IEEE Trans. Ind. Appl., vol. 46, no. 4, pp. 1332-1340, July/Aug. 2010.

[31] K. T. Chau, Q. Sun, Y. Fan, and M. Chen, "Torque ripple minimization of doubly salient permanent-magnet motors," IEEE Trans. Energy Convers., vol. 20 , no. 2 , pp. 352-359, June 2005

[32] C. C. Hwang, P. L. Li, F. C. Chuang, C. T. Liu, and K. H. Huang, "Optimization for reduction of torque ripple in an axial flux permanent magnet machine," IEEE Trans. Magn., vol. 45, no. 3, pp. 1760-1763, March 2009.

[33] K. Y. Hwang, J. H. Jo, and B. I. Kwon, "A study on optimal pole design of spoke-type IPMSM with concentrated winding for reducing the torque ripple by experiment design method," IEEE Trans. Magn., vol. 45, no. 10, pp. 4712-4715, Oct. 2009.

[34] G. Y. Sizov, D. M. Ionel, and N. A. O. Demerdash, "Modeling and design optimization of PM AC machines using computationally efficient - finite element analysis," in Proc. IEEE Energy Conversion Congress and Exposition, 2010, pp. 578-585.

[35] G. Pellegrino, and F. Cupertino, "FEA-based multi-objective optimization of IPM motor design including rotor losses," in Proc. IEEE Energy Conversion Congress and Exposition, 2010, pp. 3659-3666.

[36] Z. Q. Zhu, and D. Howe, "Instantaneous magnetic field distribution in brushless permanent magnet dc motors, part III: effect of stator slotting," IEEE Trans. Magn., vol. 29, no. 1, pp. 143-151, Jan. 1993.

[37] Z. Q. Zhu, D. Howe, and C. C. Chan, "Improved analytical model for predicting the magnetic field distribution in brushless permanent-magnet machines," IEEE Trans. Magn., vol. 38, no. 1, pp. 229-238, Jan. 2002.

[38] B. Stumberger, G. Stumberger, M. Hadziselimovic, A. Hamler, M. Trlep, V. Gorican, and M. Jesenik, "High-performance permanent magnet brushless motors with balanced concentrated windings and similar slot and pole numbers," Journal of Magnetism and Magnetic Materials, vol. 304, pp. 829-831, 2006.

[39] C. C. Hwang, S. P. Cheng, and C. M. Chang, "Design of high-performance spindle motors with concentrated windings," IEEE Trans. Magn., vol. 41, no. 2, pp. 971-973, Feb. 2005.

[40] J. Wang, Z. P. Xia, and D. Howe, "Three-phase modular permanent magnet brushless machine for torque boosting on a downsized ICE vehicle," IEEE Trans.Vehicular Technology, vol. 54, no. 3, pp. 809-816, May 2005.

[41] D. Ishak, Z. Q. Zhu, and D. Howe, "Permanent-magnet brushless machines with unequal tooth widths and similar slot and pole numbers," IEEE Trans. Ind. Appl., vol. 41, no. 2, pp. 584-590, March/April 2005.

[42] S. P. Cheng, and C. C. Hwang, "Design of high-performance spindle motors with single-layer concentrated windings and unequal tooth widths," IEEE Trans. Magn., vol. 43, no. 2, pp. 802-804, Feb. 2007.

[43] J. Xia, T. Dong, C. Wang, and J. Zhao, "Low speed high torque PMSM design based on unequal teeth structure," in Proc. $11^{\text {th }}$ int. Electric Machines and Systems Conf., pp. 3274-3277, Oct. 2008.

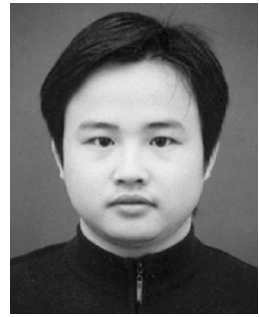

W. Fei was born in Zhejiang, China, 1981. He received the B.Eng. and M.Eng. degrees in electrical engineering from Zhejiang University, Hangzhou, China, in 2004 and 2006, respectively. $\mathrm{He}$ is currently working towards Ph.D. degree with Power and Drive Systems Group, Cranfield Defence and Security, Cranfield University, U. K.

His current research interests include design and applications of permanent-magnet machines and drives.

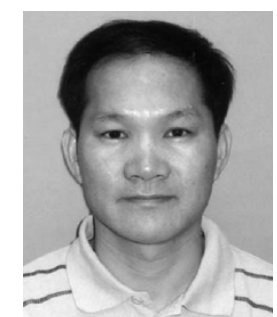

P. C. K. Luk (M'92-SM'08) was born in Hong Kong. He received his High Diploma with merit from Hong Kong Polytechnic University (PolyU) in 1983, M.Phil from Sheffield University in 1989 , and Ph.D. from Glamorgan University in 1992, all in electrical engineering.

$\mathrm{He}$ started his career in industry, first as assistant engineer during internships at GEC (HK), then as application engineer at Polytek Engineering Co. (HK). In 1986, he became a researcher at the Industrial Centre of PolyU. Since 1988, he had held academic positions at the universities of Glamorgan, Robert Gordon and Herfordshire. He joined Cranfield University as senior lecture in 2002. Currently, he is the head of Power and Drive Systems Group in the Department of Engineering and Applied Science. He has published over 100 technical papers in power electronics and motor drives. His main research interests include electrical drives for electric vehicles and renewable energy applications, and high frequency AC power distributions. 